\title{
Prey selection by the Barn Owl Tyto alba (Scopoli, 1769) in captivity
}

\author{
V. Vanitha ${ }^{1} \&$ R. Kanakasabai ${ }^{2}$ \\ 1,2 Department of Zoology, A.V.C. College, Mannampandal, Mayiladuthurai, Tamil Nadu 609305, India \\ Present address: ${ }^{2}$ Principal, Shree Raghavendra Arts \& Science College Keezhamoongiladi, Chidamparam, Tamil Nadu 608102 , India \\ Email: ${ }^{1}$ vanithabaskar@ rediffmail.com, ${ }^{2}$ ragha_gc@sancharnet.in
}

Date of online publication 26 July 2009 ISSN $0974-7907$ (online) | 0974-7893 (print)

Editor: Rajah Jayapal

\section{Manuscript details:}

Ms \# 01926

Received 21 January 2008

Final received 09 May 2009

Finally accepted 18 June 2009

Citation: Vanitha, V. \& R. Kanakasabai (2009) Prey selection by the Barn Owl Tyto alba (Scopoli, 1769) in captivity. Journal of Threatened Taxa 1(7): 361-365.

Copyright: (c) V. Vanitha \& R. Kanakasabai 2009 Creative Commons Attribution 3.0 Unported License. JoTT allows unrestricted use of this article in any medium for non-profit purposes, reproduction and distribution by providing adequate credit to the authors and the source of publication.

Author Details: V. VANITHA was a Lecturer in Zoology at the A.V.C. College (Autonomous), Mayiladuthurai. She obtained her PhD. on 'Status and management of captive Asian elephants (Elephas maximus) in Tamil Nadu, Southern India from Bharathidasan University, Tiruchirapalli, India in 2008. Her other research areas include behavioural ecology and management of captive Asian elephants.

Dr. R. Kanakasabal was the Head of the Department Zoology at the A.V.C. College (Autonomous), Mayiladuthurai. Presently he is serving as the Principal in Shree Raghavendra Arts \& Science College Chidamparam, Tamil Nadu.

Author Contribution: The first author designed and conducted the study as a partial fulfillment of her Master of Philosophy degree, while the second author supervised her research work with technica inputs as a Research Adviser.

Acknowledgement: We are thankful to Prof Rajamohan, Principal, A.V.C. College for providing all the facilities to the present study, Dr. K. Manimozhi, Dept. of Zoology, A.V.C. College for his valuable suggestions on the bio-chemical aspects analysis and Dr. K. Thiyagesan, Dept. of Zoology, A.V.C. College Mayiladuthurai and Dr. P. Neelanarayanan, Nehru Memorial College Tiruchirapalli for their technical advice in the study. We also acknowledge the valuable comments to this manuscript by Dr. G. Leonardi INFS, Bologna, Italy and Dr. R. Nagarajan, Lecturer Dept. of Zoology A.V.C. College, Mayiladuthurai.

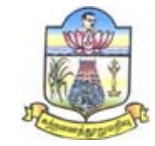

(c) (1)

OPEN ACCESS | FREE DOWNLOAD
Abstract: We investigated prey selection of the Barn Owl Tyto alba under captive conditions where birds were allowed to choose among individuals of varying size from four field rodent species: Bandicota bengalensis, Millardia meltada, Tatera indica and Mus booduga. Owls showed little species preference and a tendency to favour the medium weight class in all prey species except $M$. booduga. Preference for body parts consumed varied according to prey size, ranging from the head alone in the large weight class to the entire body in the small weight class. Biochemical measurements showed that protein, carbohydrate and lipid levels were higher respectively in the brain, liver and muscles of all three species and weight classes studied. The preference for medium weight prey despite a lower nutrient content compared to large weight prey is attributed to a greater ease of capture.

Keywords: Barn Owl, nutritional value, prey species, prey size preference.

\section{INTRODUCTION}

The Barn Owl Tyto alba (Scopoli, 1769) is one of the most widely-distributed predators of rodents (Taylor 1994; Leonardi \& Dell' Arte 2006; Neelanarayanan 2007a, b). These owls feed on a wide variety of prey and their preference varies from place to place. In the Cauvery Delta of southern India the Barn Owl mainly feeds on the Indian Mole Rat Bandicota bengalensis, Soft-furred Field Rat Millardia meltada and the House Rat Rattus rattus (Neelanarayanan 2007b). They are known to shift their prey preference between the pre-nesting and nesting seasons (Santhanakrishnan 1987). Opinions about Barn Owl feeding behaviour varies widely. Taylor (1994) stated that Barn Owls are specialists and depend mostly upon small mammals, but show considerable flexibility. On the other hand, Mikkola (1976) stated that the Barn Owl is often portrayed as an opportunistic i.e., non-selective predator. Predator prey selection may depend on the expected nutritive value of the prey, as well as the time and energy cost of searching, subduing and consuming it (Davies 1977; Griffith 1980). Studies on the feeding behaviour of Barn Owls showed that prey preference depends on the availability of species, size, sex and nutrient contents of the prey (Schoener 1969; Fast \& Ambrose 1976; Bellocq \& Kravetz 1994). According to Ille (1991) body size and energetic (nutrient) values of the prey species play a significant role in Barn Owl diet selection. A review of literature from the Indian subcontinent indicated that there is no study available on nutritive values of prey and its influence on prey selection of Barn Owls. Hence, this study was carried out under captive conditions to assess prey selection in terms of prey species, prey size and body parts of prey eaten by Barn Owls using four common field rodent species viz., Indian Mole Rat Bandicota bengalensis, Soft-furred Field Rat Millardia meltada, Indian Field Mouse Mus booduga and Indian Gerbil Tatera indica.

\section{Materials and Methods}

Study animals: The present study was carried out between December 1996 and August 1997. Four Barn Owls (2 males and 2 females) were trapped from Thiruvidaikazhi (Temple tower) village located in Cauvery Delta near Mayiladuthurai town in Nagappattinam district, Tamil Nadu. They were brought to aviary (size: 60x20x15 ft) and caged separately (size: $3 \times 3 \times 3.5 \mathrm{ft}$ ). In the aviary, one man-made nest box and a "T" shaped perching pole were placed for enriching the aviary environment in accordance with the habits of the animal. Live rats were provided ad libitum for a period of 10 days in order to acclimatize the owls to laboratory conditions. Each Barn Owl was tested individually in the aviary to observe prey preferences. The mean weight of both sexes of owls was $450 \pm 13.4 \mathrm{~g}$. The prey species viz., B. bengalensis, M. meltada, T. indica and $M$. booduga were live trapped from crop fields. 
Prey species preference (Multiple choice test): Prey species preference was studied by providing one individual from each of the four prey species of rodents to each owl. During every experiment day, one owl was allowed into the aviary in the evening (the other owls were separately caged) and the live rats were released into the aviary. The body weights of prey species supplied were 100-150g in the case of B. bengalensis and $T$. indica, and $50-75 \mathrm{~g}$ in $M$. meltada as earlier study (Santhanakrishnan 1987) shows that the Barn Owls in this area preferred these weight classes. However, in the case of $M$. booduga, the body weight of prey species supplied ranged from 18 to $20 \mathrm{~g}$ the maximum body weight for this species. The aviary was designed with precautionary measures such as smooth and vertical sidewalls, and hard floor free from holes or burrows to avoid prey species escaping from the aviary. On the subsequent morning, after caging the experimental animal, the aviary was inspected thoroughly to record details of the prey species eaten, and whether the prey was eaten fully or partly, if partly what are the parts eaten/left out. Similarly, the experiment was repeated for five days separately for each owl.

Size and body parts preference: Barn Owl's prey size preference was studied by multiple choice test. It is well established that barn owls forage on different weight classes according to prey species (Colvin \& McLean 1986; Magrini \& Facure 2008). Hence, in this experiment each prey was categorized into three weight classes according to their body weight, viz., small weight class (SW), medium weight class (MW) and large weight class (LW). The body weight ranges of prey under each weight class for the three prey species are given in Table 1 . Since $M$. booduga is relatively a small sized prey (Max. 20g body weight) compared to the others species tested, this species was not segregated into size classes. Size preferences were tested species wise. One animal of each weight class of a particular species was offered in a trial. Before feeding trials, the rats were labeled/marked at their tail with a sticker in which the sex and the weight class were written. During the trials, only one bird was allowed in the aviary and other owls were caged. Each owl was tested for five days for every experiment. On the next day, based on the prey remains in the aviary, the preferred weight class, preferred body part of the prey and weight of uneaten parts were recorded and the data so obtained were used to calculate the preference indices of various weight classes and parts. Parts selection was categorized into (1) entire prey (all parts of prey) (2) head and body (excluding tail) (3) head alone.

Biochemical studies: Total protein, carbohydrate and lipid levels in the brain, liver and muscle tissues were estimated by using the methods described by Lowry et al. (1951), Roe (1955) and Barnes \& Blackstock (1973) respectively, for three species of rodents and also for different weight classes.

Statistical Analysis: To investigate the preference of barn owls for different prey species of rodents, Jacobs' preference index (Jacob 1974) was calculated as

$$
D=\frac{r-p}{r+p-2 r p}
$$

Where $r$ is the proportion of a particular species in the diet and $\mathrm{p}$ is the proportion of that prey in the population.

Two-way ANOVA was used to assess difference in the three
Table 1. Details of rodent prey species, size classes and their weights $(\mathrm{g})$ used in the present study

\begin{tabular}{lccc}
\hline Prey size class & \multicolumn{3}{c}{ Rodent prey species } \\
& Bandicota bengalensis & Millardia meltada & Tatera indica \\
\hline Small weight (SW) & $50-100$ & $25-50$ & $50-100$ \\
Medium weight (MW) & $100-150$ & $50-75$ & $100-150$ \\
Large weight (LW) & $150-200$ & $75-100$ & $150-200$ \\
\hline
\end{tabular}

Table 2. Relative preference of different prey species by the Barn Owl (Tyto alba) under multiple-choice experiments (four owls tested with five trials each)

\begin{tabular}{lccl}
\hline Prey species & \multicolumn{3}{c}{ Mean preference (\%) } \\
& Absolute & Relative & Jacobs' \\
\hline Bandicota bengalensis & 90.6 & 29.0 & 0.10 \\
Millardia meltada & 86.8 & 27.8 & 0.07 \\
Tatera indica & 74.9 & 24.0 & -0.03 \\
Mus booduga & 60.0 & 19.2 & -0.168 \\
\hline
\end{tabular}

Table 3. Preference (percent biomass consumed) of different weight classes of prey species by the Barn Owl T. alba

\begin{tabular}{|c|c|c|c|}
\hline \multirow[t]{2}{*}{ Prey species } & \multirow[t]{2}{*}{ Weight class (g) } & \multicolumn{2}{|c|}{ Mean preference index (\%) } \\
\hline & & Absolute & Relative \\
\hline \multirow{3}{*}{ B. bengalensis } & Small (50-100) & 65.3 & 32.2 \\
\hline & Medium (100-150) & 89.7 & 44.3 \\
\hline & Large (150-200) & 47.5 & 23.5 \\
\hline \multirow{3}{*}{ M. meltada } & Small (25-50) & 60.0 & 24.9 \\
\hline & Medium (50-75) & 97.8 & 40.5 \\
\hline & Large $(75-100)$ & 83.4 & 34.6 \\
\hline \multirow{3}{*}{ T. indica } & Small (50-100) & 75.0 & 34.7 \\
\hline & Medium (100-150) & 89.8 & 41.5 \\
\hline & Large (150-200) & 51.5 & 23.8 \\
\hline
\end{tabular}

nutrient levels of the organs and weight classes of three prey species. There were significant differences in nutrient levels among the three weight classes and organs. Therefore, Least Significant Difference (LSD), a post-hoc multiple comparison test was used to examine the difference among a pair of means independent of the number and magnitude of the means (Sokal \& Rohlf 1981).

\section{Observations and Results}

Prey species preference: The Barn Owl seemed to have more preference for B. bengalensis (29\%) and M. meltada (27.8\%), while the T. indica and the field mouse, M. booduga were the least preferred diets as their relative preference index values were respectively $24 \%$ and $19.2 \%$ only, which was confirmed by Jacobs' Preference Index (Table 2).

Prey size preference: When B. bengalensis and T. indica were offered, the Barn Owls preferred mostly the medium weight class, followed by smaller weight class and rarely large weight class (Table 3). In the case of M. meltada, the Barn Owl preferred mostly medium weight class followed by large weight class and smaller weight class.

It is apparent from the results that rodents which grew up to $200 \mathrm{~g}$ (B. bengalensis, and T. indica) the order of preference by Barn Owl was medium weight class $>$ small weight class $>$ large weight class. On the other hand, in the case of M. meltada 
Table 4. Variations in the percent use of different body parts of the three prey species (when offered with three weight classes) by the Barn Owl T. alba (prey species were offered as single choice)

\begin{tabular}{|c|c|c|c|c|c|}
\hline \multirow[t]{2}{*}{ Prey species } & \multirow[t]{2}{*}{ Weight class (g) } & \multirow{2}{*}{$\begin{array}{l}\text { Mean weight } \\
\text { (g) }\end{array}$} & \multicolumn{3}{|c|}{ Mean percent consumed } \\
\hline & & & Entire- prey & Head and body & Head alone \\
\hline \multirow{3}{*}{ B. bengalensis } & Small (50-100) & 77.5 & 78.7 & 9.9 & 一 \\
\hline & Medium (100-150) & 135.0 & 一 & 53.5 & 8.9 \\
\hline & Large (150-200) & 177.5 & 一 & 9.4 & 38.7 \\
\hline \multirow{3}{*}{ M. meltada } & Small $(25-50)$ & 34.2 & 100.0 & - & - \\
\hline & Medium (50-75) & 65.8 & 21.2 & 64.9 & 一 \\
\hline & Large $(75-100)$ & 100.0 & 一 & 32.6 & 19.9 \\
\hline \multirow{3}{*}{ T. indica } & Small (50-100) & 77.5 & 69.4 & 11.8 & - \\
\hline & Medium (100-150) & 125.8 & - & 48.8 & 8.6 \\
\hline & Large (150-200) & 184.2 & - & 8.5 & 37.8 \\
\hline
\end{tabular}

Table 5. Nutrient contents $(\mathrm{mg} / \mathrm{g})$ in the brain, liver and muscle of the three weight classes of the three prey species (horizontal lines connect similar means (Least Significant Difference (LSD) was used for comparison) and results of twoway ANOVA show the effect of organ types and weight classes on the three nutrients levels

\begin{tabular}{|c|c|c|c|c|c|c|c|c|c|}
\hline \multirow[t]{3}{*}{ Prey species } & \multirow[t]{3}{*}{ Nutrient $(\mathrm{mg} / \mathrm{g})$} & \multirow[t]{3}{*}{ Tissue } & \multicolumn{3}{|c|}{ Weight class } & \multicolumn{4}{|c|}{ ANOVA $(d f=2)$} \\
\hline & & & \multirow{2}{*}{ Small } & \multirow[t]{2}{*}{ Medium } & \multirow[t]{2}{*}{ Large } & \multicolumn{2}{|c|}{ Organ } & \multicolumn{2}{|c|}{ Weight class } \\
\hline & & & & & & $\boldsymbol{F}$ & $p$ & $F$ & $p$ \\
\hline \multirow{9}{*}{ B. bengalensis } & \multirow[t]{3}{*}{ Protein } & Brain & 51.3 & 62.5 & 72.6 & \multirow{3}{*}{151} & \multirow{3}{*}{$<0.05$} & \multirow{3}{*}{125} & \multirow{3}{*}{$<0.05$} \\
\hline & & Liver & 42.4 & 54.9 & 64.0 & & & & \\
\hline & & Muscle & 33.3 & 42.5 & 47.7 & & & & \\
\hline & \multirow[t]{3}{*}{ Carbohydrate } & Brain & 12.6 & 18.1 & 24.1 & \multirow{3}{*}{15.0} & \multirow{3}{*}{$<0.05$} & \multirow{3}{*}{114} & \multirow{3}{*}{$<0.05$} \\
\hline & & Liver & 12.7 & 23.0 & 26.5 & & & & \\
\hline & & Muscle & 11.4 & 16.6 & 22.0 & & & & \\
\hline & \multirow[t]{3}{*}{ Lipid } & Brain & 57.0 & 116.9 & 170.4 & \multirow{3}{*}{13.5} & \multirow{3}{*}{$<0.05$} & \multirow{3}{*}{93.6} & \multirow{3}{*}{$<0.05$} \\
\hline & & Liver & 84.4 & 121.4 & 170.4 & & & & \\
\hline & & Muscle & 96.9 & 152.2 & 210.3 & & & & \\
\hline \multirow{9}{*}{ M. meltada } & \multirow[t]{3}{*}{ Protein } & Brain & 18.3 & 36.6 & 53.6 & \multirow{3}{*}{108.9} & & & \\
\hline & & Liver & 14.7 & 30.8 & 45.2 & & $<0.05$ & 133 & $<0.05$ \\
\hline & & Muscle & 12.5 & 28.9 & 37.8 & & & & \\
\hline & Carbohydrate & Brain & 6.9 & 9.9 & 14.9 & & & & \\
\hline & & Liver & 7.7 & 10.8 & 16.2 & 20.0 & $<0.05$ & 189 & $<0.05$ \\
\hline & & Muscle & 5.6 & 8.7 & 13.4 & & & & \\
\hline & Lipid & Brain & 102.6 & 128.2 & 165.3 & & & & \\
\hline & & Liver & 88.9 & 142.5 & 184.1 & 13.5 & $<0.05$ & 209 & $<0.05$ \\
\hline & & Muscle & 107.7 & 152.1 & 197.7 & & & & \\
\hline & Protein & Brain & 50.4 & 57.5 & 62.9 & & & & \\
\hline & & Liver & 43.8 & 51.3 & 59.2 & 329.4 & $<0.05$ & 144 & $<0.05$ \\
\hline & & Muscle & 31.9 & 37.6 & 43.4 & & & & \\
\hline T. indica & Carbohydrate & Brain & 11.0 & 13.8 & 17.7 & & & & \\
\hline & & Liver & 13.6 & 15.3 & 18.1 & 101.9 & $<0.05$ & 137 & $<0.05$ \\
\hline & & Muscle & 9.5 & 11.4 & 13.3 & & & & \\
\hline & Lipid & Brain & 43.9 & 83.8 & 114.6 & & & & \\
\hline & & Liver & 79.2 & 103.2 & 129.9 & 252.3 & $<0.05$ & 185.0 & $<0.05$ \\
\hline & & Muscle & 118.6 & 153.9 & 184.6 & & & & \\
\hline
\end{tabular}

that grew up to $100 \mathrm{~g}$, the preferential order was medium weight class $>$ large weight class $>$ small weight class. It is obvious from the results that the prey in the 50 to $150 \mathrm{~g}$ size is the preferred size for Barn Owls (Table 3). There is less preference for prey below $50 \mathrm{~g}$ as seen in the case of $M$. booduga and also for prey above the $150 \mathrm{~g}$ class as seen in the other two species.

Preference of body parts of prey: Barn Owl's prey parts selection varied according to prey size class (Table 4). Owls swallowed mostly entire body in all the three species when the prey size was in small weight class (B. bengalensis 79\%, M. meltada $100 \%$, T. indica $69 \%$ ). On the other hand, in the medium weight class prey, the owls fed mostly on head and body portions and excluded tail (B. bengalensis 54\%, M. meltada $65 \%$ and $T$. indica $49 \%)$. In the case of larger prey weight class, owl preferred mostly head portion of B. bengalensis $39 \%$ and T. indica $38 \%$ and as an exception the head and body parts for M. meltada (33\%). In general, Barn Owl consumed mostly the entire prey in the smaller size class, head and body in the medium weight class and head alone in the larger weight class prey.

\section{Biochemical estimation}

i. Quantitative estimation of protein: The brain had higher protein content than the liver and muscle in all weight classes of different rodent species (Table 5). Among the three species of rodents, protein content of brain, liver and muscle in the three size classes was highest in $B$. bengalensis (except liver of small weight class) followed by $T$. indica and M. meltada. In the case of $M$. booduga, also a similar trend in protein content was observed (Table 6).

ii. Quantitative estimation of carbohydrate: Generally, 
Table 6. Nutrient contents $(\mathrm{mg} / \mathrm{g})$ of the brain, liver and muscle of $M$. booduga

\begin{tabular}{|c|c|c|c|}
\hline Nutrient $(\mathrm{mg} / \mathrm{g})$ & Brain & $\begin{array}{l}\text { Body parts } \\
\text { Liver }\end{array}$ & Muscle \\
\hline Protein & $44.50 \pm 03.70$ & $36.10 \pm 01.90$ & $34.80 \pm 01.90$ \\
\hline Carbohydrate & $07.70 \pm 00.30$ & $09.30 \pm 00.40$ & $07.30 \pm 00.30$ \\
\hline Lipid & $73.70 \pm 02.90$ & $81.30 \pm 03.70$ & $107.50 \pm 05.40$ \\
\hline
\end{tabular}

carbohydrate content was greater in the liver than in the brain and muscle of all weight classes and prey species (Table 5). Among the three prey species, carbohydrate level was highest in liver, brain and muscle of B. bengalensis (except in liver of small weight class compared to $T$. indica) followed by $T$. indica and $M$. meltada. Liver had the highest content of carbohydrate even in the case of $M$. booduga (Table 6).

iii. Quantitative estimation of lipid: Unlike protein and carbohydrate, lipid level was highest in the muscles relative to the brain and liver of all weight classes and rodent species studied. A comparison of lipid content among the three rodent species showed that $M$. meltada had higher lipid content for most classes (except in brain of large weight class) compared to B. bengalensis and T. indica (Table 5).

The three nutrients viz., protein, carbohydrate and lipid showed significant differences between different weight class and also between the different organs studied (Two-way Anova $p<0.05$ ) (Table 5). A pair-wise comparison (by LSD) of the three nutrients among the three weight classes showed that the brain, liver and muscle of large weight classes had significantly higher protein than that of the other two classes in all the three species except for the muscle of B. bengalensis (Table 5). There were significant variations in carbohydrate levels, with reference to size classes (the large weight class had the highest values) in all the three species except for liver in B. bengalensis (Table 5). Similarly, the lipid level was also significantly higher in the large weight class compared to the other two classes for all the three organs in all the species (Table 5).

\section{Discussion}

The Jacobs' preference index indicated that the barn owl's preference among the four prey species were B. bengalensis $>M$. meltada $>$ T. indica $>M$. booduga, which is similar to the pattern of diet selection in natural habitat by Barn Owls (Neelanarayanan et al. 1995; Neelanarayanan 2007b). Although Barn Owls in the present experiment consumed all four species, a relatively higher consumption of $B$. bengalensis and $M$. meltada among the four species tested is in accordance with the findings of Neelanarayanan (2007b) in the natural habitats of Cauvery Delta, who attributed such preference to abundance of these species in crop fields. However, in the present study all the four prey species were supplied in equal number (one individual from each species in multiple choice test), the owls still consumed more B. bengalensis and M. meltada, suggesting prey abundance may not be the only major factor influencing the diet selection as reported elsewhere on barn owls (Colvin 1984; Yom-Tov \& Wool 1997; Leonardi \& Dell' Arte 2006). Other factors that could influence the prey selection by Barn Owls are habitat type (Colvin et al. 1984; Santhanakrishnan 1987), reproductive status of owl (Santhanakrishnan 1987), body size and energetic (nutrient) values of the prey species (Ille 1991). However, since the present study was conducted under captive conditions, factors such as habitat type and reproductive status are controlled and the choices are restricted only to species, size-class and nutrient value.

In the prey choice test, there was strong preference for the medium size class of B. bengalensis, and T. indica (100-150g) and $M$. meltada (50-75g). The findings of the present investigation corroborate with those of Morris (1979), Hamilton \& Neil (1981) and Santhanakrishnan (1987), who also reported the higher preference of medium weight class of almost all rodent prey species. The possible reasons for the selection of medium weight class could be a function of easy handling and swallowing the prey and efficiency in carrying the prey to its nests as reported by Colvin (1984). Since the energy gain of the Barn Owl depends upon the energy spent, the process of capturing larger prey may not compensate the energy gain (Colvin 1984) and thus the owls may have avoided spending higher energy in capturing the large prey. According to Krebs (1978) the large prey items are not always optimal for a predator, because they require more handling time than smaller items. Similarly, the least preference shown to small weight class could also be due to the lower energy gain relative to the energy spent on hunting the smaller prey, as reported by Taylor (1994). The intermediate class prey may give optimal reward, as they provide better balance of capture/handling time for energy gained (Davies 1977). Hence, the preference of barn owl to medium weight class individuals in all the prey species might be based on profitability (Ille 1991), which in turn depends on hunting, handling and subduing of the prey (Colvin \& McLean 1986) resulting in a strategy of compromise between all the above factors. Further in the present study, Barn Owls mostly swallowed whole prey when the prey size was small. In the medium sized prey, owls fed mostly the head and the body portion, while in the large sized prey, the owls consumed only head portion. The reason for the selective feeding on various parts in different weight classes of the prey could be the function of required quantity of food and the gut capacity along with nutrient quantity available in different parts of the prey. For example when the prey size is larger than the gut capacity, owls select parts that contain higher quantity of energy, as owls preferred the head in larger sizeclass prey, which had higher protein than other parts of prey as shown by the study. Therefore, the selective partial feeding in larger and medium sized prey could be attributed to higher profitability, as speculated by Ille (1991). So it can be reasonably concluded that the barn owl's preference to medium size prey and selective feeding on certain body parts in the case of large prey, could be due to their relatively higher energy profitability.

\section{References}

Barnes, H. \& J. Blackstock (1973). Estimation of lipids in marine animals tissues: Detailed investigation of the sulphophosphovanillin method for total lipids. Journal of Experimental Marine Biology and Ecology 12: 103-118

Bellocq, M.I. \& F.O. Kravetz (1994). Feeding strategy and predation of the barn owl (Tyto alba) and the burrowing owl (Speotyto cunicularis) on rodent species, sex and size in agro-system of Central Argentina. Ecologia Australia 4(1): 29-34.

Colvin, B.A. (1984). Barn owl foraging behaviour and secondary 
poisoning hazard from rodenticide use on farms. PhD Thesis. Bowling Green State University, Bowling Green Ohio, 326pp.

Colvin, B.A., P.L. Hegdal \& W.B. Jackson (1984). A comprehensive approach to research and management of common Barn owl populations, pp 270-282. In: McComb, W. (ed.). Proceeding of Workshop on management of non-game species and ecological communities. 1984 June 11-12; University of Kentucky, Lexington, 564pp.

Colvin, B.A. \& E.B. MacLean (1986). Food habits and prey specificity of the common barn owl in Ohio. Ohio Journal of Science 86 (1): 7680 .

Davies, N.B. (1977). Prey selection and the search strategy of the spotted flycatcher (Muscicapa striata): A field study on optimal foraging. Animal Behaviour 25: 1016-1033.

Errington, P.L. (1967). Of Predation and Life. Iowa State University Press. Ames, IA, USA., 277pp.

Fast, S.J. \& H.W. Ambrose (1976). Prey preference, hunting and habitat selection in the barn owl. The American Midland Naturalist 96: 503507 .

Griffith, D. (1980). Foraging costs and relative prey size. The American Naturalist 116: 743-752.

Hamilton, K.L. \& R.L. Neil (1981). Food habits and bioenergetics of a pair of barn owls and owlets. The American Midland Naturalist 106: 19.

Ille, R. (1991). Preference of prey size and profitability in barn owls in central Chile and southern Spain: A comparative study. Behaviour 116: $180-189$.

Jacob, J. (1974). Quantitative measurements of food selection: a modification of the forage ratio and Ivlev's electivity index. Oecologica 14: 413-417.

Krebs, J.R. (1978). Optimal foraging: decision rules for predators, pp 263. In Krebs, J.R. \& N.B. Davies (eds.) Behavioural Ecology: an evolutionary approach. Blackwell Publication, Oxford 420pp.

Leonardi, G. \& G.L. Dell'Arte (2006). Food habitats of barn owl (Tyto alba) in a steppe area of Tunisia. Journal of Arid Environments 65: $677-681$

Lowry, O.H., N.J. Rosebrough, A.L. Farr \& R.J. Randall (1951). Protein measurements with the folin-phenol reagent. Journal of Biological Chemistry 193: 265-275.
Magrini, L. \& K.G. Facure (2008). Barn owl (Tyto alba) predation on small mammals and its role in the control of hantavirus natural reservoirs in a periurban area in southern Brazil. Brazil Journal of Biology 68(4): 733-740.

Mikkola, H. (1976). Owls killing and killed by other owls and raptors in Europe. British Birds 69: 144-154.

Morris, P. (1979). Rats in the diet of Barn owl (Tyto alba). Journal of the Zoological Society of London 189: 540-545.

Neelanarayanan, P. (2007a). Technique for estimation of barn owl (Tyto alba stertens Hartert, 1929) prey biomass with special reference to mandible length-body weight ratio of small mammals. Zoos' Print Journal 22(1): 2519-2521.

Neelanarayanan, P. (2007b). Diet of barn owl Tyto alba stertens Hartert, 1929 in a portion of Cauvery Delta, Tamil Nadu, India. Zoos' Print Journal 22(8): 2777-2781.

Neelanarayanan, P., R. Nagarajan \& R. Kanakasabai (1995). The common barn owl, Tyto alba: A potential predator of rodent pests. Pestology 19(9): 34-37.

Newsome, A. (1990). The control of vertebrate pests by vertebrate predator. Trends in Ecology and Evolution 5(6): 187-191.

Roe, J.R. (1955). The determination of sugar in blood and spinal fluid with another reagent. Journal of Biological Chemistry 20: 335-343.

Santhanakrishnan, R. (1987). Studies on population, food habits and nesting of Barn owl, Tyto alba (Scopoli) in a portion of Cauvery basin. M.Phil Thesis, A.V.C. College, Bharathidasan University, Tiruchirapally. (Unpublished)

Schoener, T.W. (1969). Models of optimal size for solitary predator The American Naturalist 103: 277-313.

Sokal, R.R. \& F.J. Rohlf (1981). Biometry. Second Edition, W. H. Freeman and Company, New York. 859pp.

Taylor, I. (1994). Barn owls: Predator Prey Relationship and Conservation. Cambridge University Press, 304pp.

Yom-Tov, Y. \& D. Wool (1997). Do the content of barn owls pellets accurately represent the proportion of prey species in the field. Condor 99: 972-976. 